\title{
First flush of storm runoff pollution from an urban catchment in China
}

\author{
LI Li-qing ${ }^{1}$, YIN Cheng-qing ${ }^{1, *}$, HE Qing-ci ${ }^{2}$, KONG Ling-li ${ }^{2}$ \\ 1. State Key Laboratory of Environmental Aquatic Chemistry, Research Center for Eco-Environmental Sciences, \\ Chinese Academy of Sciences, Beijing 100085, China. E-mail: li-liqing@163.com \\ 2. Wuhan Research Institute of Environmental Science, Wuhan 430015, China
}

Received 31 March 2006; revised 22 May 2006; accepted 9 June 2006

\begin{abstract}
Storm runoff pollution process was investigated in an urban catchment with an area of $1.3 \mathrm{~km}^{2}$ in Wuhan City of China. The results indicate that the pollutant concentration peaks preceded the flow peaks in all of 8 monitored storm events. The intervals between pollution peak and flow peak were shorter in the rain events with higher intensity in the initial period than those with lower intensity. The fractions of pollution load transported by the first $30 \%$ of runoff volume $\left(\mathrm{FF}_{30}\right)$ were $52.2 \%-72.1 \%$ for total suspended solids (TSS), $53.0 \%-65.3 \%$ for chemical oxygen demand (COD), 40.4\%-50.6\% for total nitrogen (TN), and 45.8\%-63.2\% for total phosphorus (TP), respectively. Runoff pollution was positively related to non-raining days before the rainfall. Intercepting the first $30 \%$ of runoff volume can remove $62.4 \%$ of TSS load, $59.4 \%$ of COD load, $46.8 \%$ of TN load, and $54.1 \%$ of TP load, respectively, according to all the storm events. It is suggested that controlling the first flush is a critical measure in reduction of urban stormwater pollution.
\end{abstract}

Key words: first flush; stormwater pollution; urban area; rainfall pattern; runoff

\section{Introduction}

Urban storm runoff was identified as one of the leading causes of degradation in the quality of receiving waters (US EPA, 1998). Storm runoff from urban area contains various pollutants, as well as carries a large pollutant load, so it exerts a great influence on receiving waters (Characklis and Wiesner, 1997).

In recent years, with a rapid urbanization in China, many water bodies within cities are either eutrophic, with excess algae biomass, or oxygen depleted. Much attention has been paid to the control of the pollution from urban and industrial wastewaters through the establishment of treatment plants. As the treatment facilities of point sources expand, the relative importance of urban runoff pollution on receiving waters is increasing. Urban runoff pollution problems are more difficult to control than steady-state point discharges because of the intermittent nature of rainfall and runoff, the large variety of pollutant source types, and the variable nature of source loadings. Urban runoff pollution has been studied in developed countries (Gnecco et al., 2005; Suarez and Puertas, 2005). However, little information is available on storm runoff pollution from urban area in developing counties, including China.

The objectives of this study conducted in Wuhan City were (1) to characterize the discharge of storm runoff pollution from an urban catchment; (2) to find the relationship

Project supported by the Hi-Tech Research and Development Program (863) of China (No. 2002AA601022). *Corresponding author.

E-mail: cqyin@263.net. between the pollution process and the rainfall patterns.

\section{Materials and methods}

\subsection{Study area}

This study was conducted in a catchment, Shilipu, in Wuhan City, China. The climate is typically subtropical monsoon climate with a mean annual temperature of $15.9^{\circ} \mathrm{C}$ and the mean annual precipitation of $1300 \mathrm{~mm}$. Most of the rain occurs during the period from April to August of each year. Wuhan City has 147 lakes with an area more than $0.1 \mathrm{~km}^{2}$.

Shilipu catchment is located on the north bank of the Moshuihu Lake with an area of $4.8 \mathrm{~km}^{2}$, seriously eutrophicated caused by the untreated wastewater discharge and urban storm runoff pollution. The catchment is a typical urban area with a population density of 130 per hectare and the ground impervious ratio of $85 \%$. The catchment has a combined sewer system. Wastewater treatment plant is being constructed to intercept wastewater for treatment. But the wastewater from this catchment is not intercepted and directly discharged into the nearest Moshuihu Lake during the period of experiments. Large amount of urban storm runoff mixed with wastewater is also discharge into Moshuihu Lake during the raining days.

\subsection{Sampling and analyses}

Samples were taken from 8 rainfall events from April to August in 2005. Samples were collected at the pipe outlet, beginning at the initiation of the rain event and ending 
when the flow receded down to the dry weather water level. Sampling intervals was $5 \mathrm{~min}$ in the first $30 \mathrm{~min}$, and then the interval was $10 \mathrm{~min}$. The discharge of runoff was continuously measured through rectangular weir constructed from outlet of the pipe. The flow rates were calculated by velocity and cross area. Rainfall intensity was recorded by an automated gauge in the nearby work station. Rainfall patterns of sampling events were summarized in Table 1.

The samples were treated and analyzed in the laboratory of work station. Total suspended solids (TSS) and chemical oxygen demand (COD) were measured according to standard methods of APHA (1998). The unfiltered water samples were digested with $\mathrm{K}_{2} \mathrm{~S}_{2} \mathrm{O}_{7}$ solution for determination of total nitrogen (TN) and total phosphorus (TP) concentrations (Ebina et al., 1983).

\section{Results}

\subsection{Temporal variation of pollutants over runoff events}

Combining runoff quantity and quality data of each storm event can produce a set of hydrograph and pollutograph for TSS, COD, TN, and TP. Figs. 1 and 2 show the actual flow and concentrations of TSS, COD, TN, and TP during two storm events of August 3, 2005 (41.3 mm) and

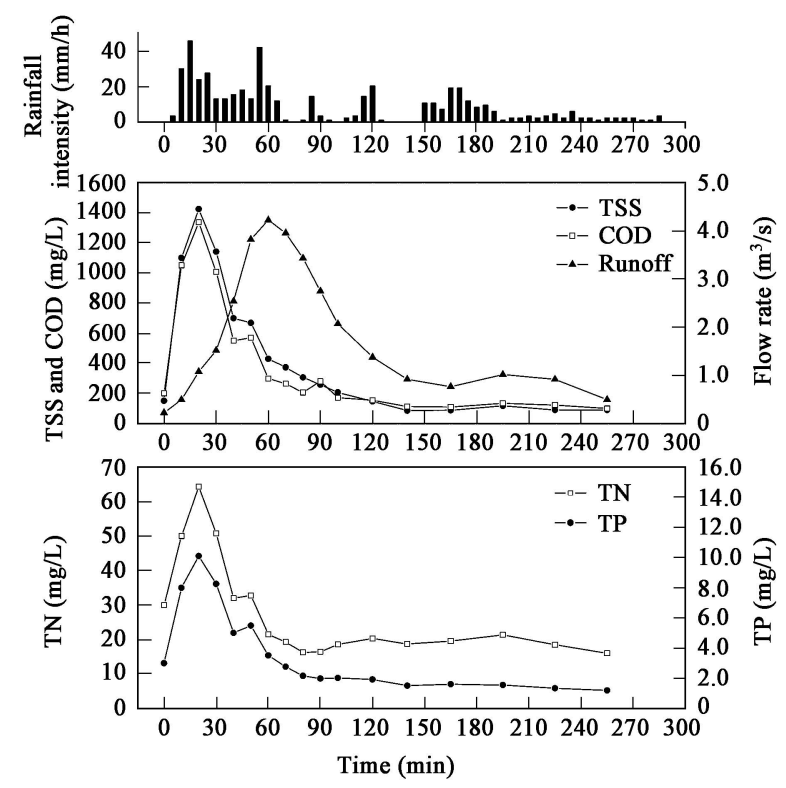

Fig. 1 Development of flow and concentration of TSS, COD, TN, and TP during storm event of August 3, 2005 (41.3 mm).

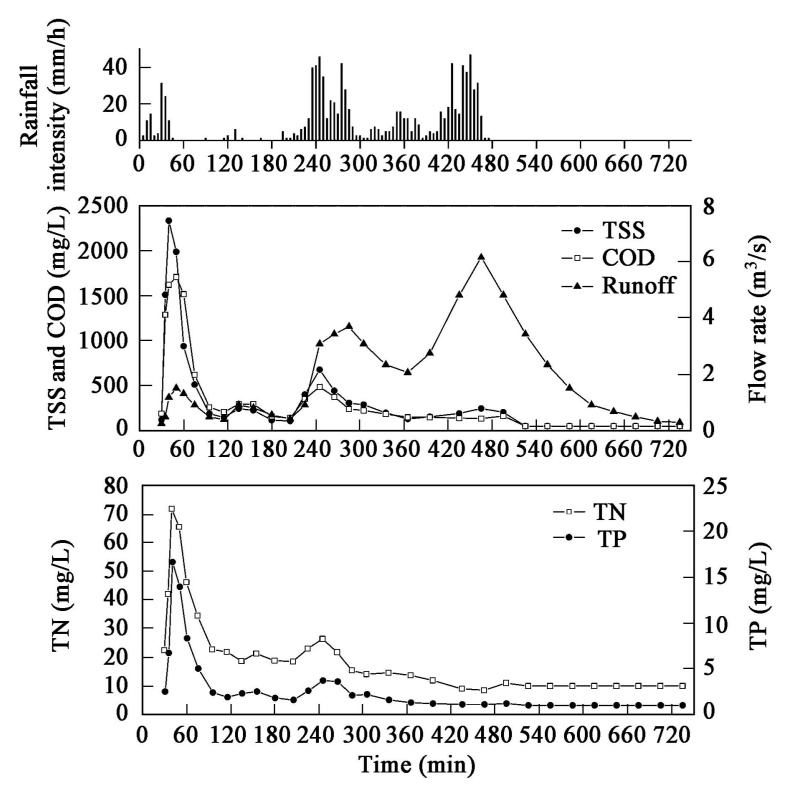

Fig. 2 Development of flow and concentration of TSS, COD, TN, and TP during storm event of June 26, 2005 (78.0 mm).

June 26, 2005 (78.0 mm), respectively. The rain event of August 3, 2005 was high intensity in the initial period of event, whereas the rain event of June 26, 2005 was high intensity in the later period of event.

The pollutant concentration peak preceded the flow peak in the both events. After the peak, the pollutant concentration rapidly reduced. The interval between the pollution peak and flow peak was $40 \mathrm{~min}$ in the event of August 3, 2005. The interval between the pollution peak and flow peak was $415 \mathrm{~min}$ in the event of June 26, 2005 because the highest intensity rainfall concentrated in the later period. The rain pattern influenced the interval between the pollution peak and flow peak. The phenomena of first flush also occurred for other storm events monitored in Shilipu catchment. The intervals of each storm events with different rain patterns are shown in Table 2. The interval was shorter in the rainfalls with higher intensity during the initial period of the event. The results suggest that the higher first flush is more likely to be associated with more intensive events.

\subsection{Pllutants load distribution in the storm runoff}

Pollution load delivery was not proportional to the amount of runoff volume in urban runoff process. A high delivery of pollution load occurred during the early portion

Table 1 Rainfall parameters for each of the storm events sampled in 2005

\begin{tabular}{lccccc}
\hline No. & Date of rain event & $\begin{array}{c}\text { Rainfall } \\
(\mathrm{mm})\end{array}$ & $\begin{array}{c}\text { Duration } \\
(\mathrm{h})\end{array}$ & $\begin{array}{c}\text { Average intensity } \\
(\mathrm{mm} / \mathrm{h})\end{array}$ & $\begin{array}{c}\text { Maximum intensity } \\
(\mathrm{mm} / \mathrm{h})\end{array}$ \\
\hline 1 & $4 / 8$ & 18.8 & 1.8 & 10.4 & 40.8 \\
2 & $5 / 1$ & 10.5 & 2.3 & 4.6 & 31.2 \\
3 & $5 / 17$ & 32.0 & 2.5 & 12.8 & 32.4 \\
4 & $6 / 10$ & 35.0 & 3.1 & 11.3 & 40.8 \\
5 & $6 / 26$ & 78.0 & 7.9 & 9.9 & 46.8 \\
6 & $7 / 10$ & 30.1 & 4.0 & 2.5 & 54.0 \\
7 & $7 / 22$ & 27.0 & 1.2 & 8.6 & 15 \\
8 & $8 / 3$ & 41.3 & 4.8 & 13 & 82.8 \\
\hline
\end{tabular}

*Antecedent dry weather period are considered days with storms less than $10 \mathrm{~mm}$. 
Table 2 Interval between the pollution peak and flow peak appearance time for eight rain events

\begin{tabular}{|c|c|c|c|c|c|}
\hline Date of rain event & $\begin{array}{c}\text { Time of pollution } \\
\text { peak appearance }(\mathrm{min})\end{array}$ & $\begin{array}{l}\text { Time of flow peak } \\
\text { appearance (min) }\end{array}$ & $\begin{array}{l}\text { Interval time } \\
\quad(\min )\end{array}$ & $\begin{array}{l}\text { Maximum rainfall } \\
\text { intensity }(\mathrm{mm} / \mathrm{h})\end{array}$ & $\begin{array}{c}\text { Time of maximum rainfall } \\
\text { intensity ( } \mathrm{min})\end{array}$ \\
\hline $4 / 8$ & 10 & 30 & 20 & 40.8 & 15 \\
\hline $5 / 1$ & 40 & 50 & 10 & 31.2 & 30 \\
\hline $5 / 17$ & 20 & 95 & 75 & 32.4 & 75 \\
\hline $6 / 10$ & 65 & 100 & 35 & 40.8 & 75 \\
\hline $6 / 26$ & 50 & 465 & 415 & 46.8 & 450 \\
\hline $7 / 10$ & 80 & 120 & 40 & 54.0 & 110 \\
\hline $7 / 22$ & 40 & 90 & 50 & 82.8 & 50 \\
\hline $8 / 3$ & 15 & 55 & 40 & 45.6 & 10 \\
\hline
\end{tabular}

The time of pollution peak, flow peak, and maximum rainfall intensity appearance was from the start of the event.
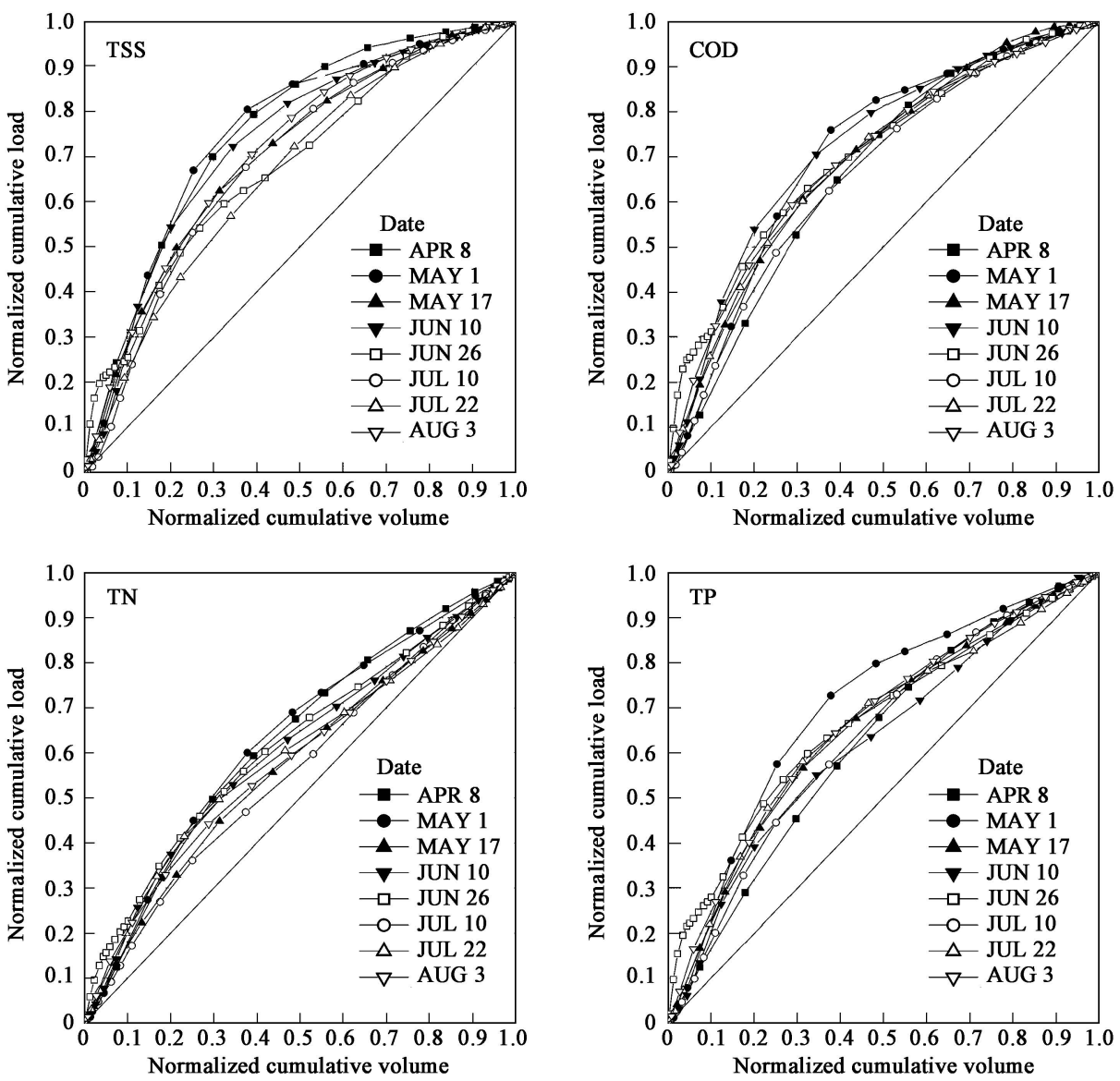

Fig. 3 Normalized cumulative curves for TSS, COD, TN, and TP of eight storm events.

of storm runoff as shown by the pollutants load cumulative distribution in storm runoff in dimensionless (Fig.3). The plot of the distribution of pollutant load with volume revealed the variation of the fraction of the pollutant load that removed from the catchment in relation to the fraction of runoff volume that left the catchment throughout storm events. If the rate that pollutants were washed from the catchment is proportional to the runoff, the curves for load to runoff will be consistent with the bisector line. If the rate of pollution load is higher than that of storm runoff, the curves will be above the dissector line. The curves of four water quality parameters for eight storm events all were above the bisector line, which suggests that the large fractions of pollutants load were transported by the initial parts of runoff volume. The difference between the curves and the bisector can be used to indicate the magnitude of first flush. Since the difference maximum for each event was around the $30 \%$ of normalized runoff, the pollution load transported by the first $30 \%$ of runoff volume $\left(\mathrm{FF}_{30}\right)$ can be used as an indicator to evaluate the magnitude of first flush for different storm events and pollutants. The mean values, extreme values, standard deviations, variation coefficients of $\mathrm{FF}_{30}$ are presented in Table 3. The means of

Table 3 Statistical summary of $\mathrm{FF}_{30}$ values of TSS, COD, TN and TP

\begin{tabular}{lllll}
\hline & TSS & COD & TN & TP \\
\hline Mean (\%) & 62.4 & 59.4 & 46.8 & 54.1 \\
Maximum (\%) & 72.1 & 65.3 & 50.6 & 63.2 \\
Minimum (\%) & 52.2 & 53.0 & 40.4 & 45.8 \\
Standard deviation (\%) & 6.8 & 4.3 & 3.6 & 5.4 \\
Variation coefficient (\%) & 10.9 & 7.2 & 7.7 & 10.0 \\
\hline
\end{tabular}

$\mathrm{FF}_{30}$ : The pollution land transported by the first $30 \%$ of runoff volume. 
$\mathrm{FF}_{30}$ values of TSS, COD, TN, and TP are $62.4 \%, 59.4 \%$, $46.8 \%$, and $54.1 \%$, respectively. The fractions of pollutants load transported by the first $30 \%$ of runoff volume are high, especially for TSS and COD. The magnitudes of first flush of TSS and COD are stronger than those for TN and TP. It can be concluded that solids and organic matter are the main pollutants in storm runoff discharges of Shilipu catchment.

\section{Discussion}

The phenomenon of first flush was caused by the first part of runoff, flushing off the accumulated pollutants from the urban surface and sewers before the large part of runoff arrived at the outfall. The first flush is influenced by many factors, such as a watershed area, rainfall intensity, impervious area, antecedent dry weather period (Taebi and Droste, 2004).

The $\mathrm{FF}_{30}$ value of TSS, as a measure of first flush, was correlated to each of the rain-runoff characteristics. The rainfall depth $(P)$, the total time of rainfall duration $\left(T_{\mathrm{r}}\right)$, event average rainfall intensity $(I)$, event maximum rainfall intensity $\left(I_{\max }\right)$, event aggregate volume of runoff $(V)$, and the antecedent dry weather period (ADWP) were chosen. The antecedent dry weather period was selected and considered in this study because in the cities of China including Wuhan City combined sewer system is very prevail. Other reasons are more littering and using manual sweeping activities for all dry weather conditions in Shilipu catchment. Thus the amount of pollutants accumulated in the catchment is likely to be related with the antecedent dry weather period.

The results for linear coefficients, $R$, their corresponding $p$-values, $p$, rank correlation coefficients, $R_{\mathrm{r}}$, and their corresponding $p$-values, $p_{\mathrm{r}}$, are given in Table 4 . The results of line correlation and Sperman rank correlation are very similar.

Table 4 Correlation coefficients between the first flush loads of total suspended solids $\left(\mathrm{FF}_{30}\right.$ of TSS) and storm event characteristics

\begin{tabular}{lllll}
\hline & $R$ & $p$ & $R_{\mathrm{r}}$ & $p_{\mathrm{r}}$ \\
\hline$P$ & -0.52 & 0.19 & -0.43 & 0.29 \\
$T_{\mathrm{r}}$ & -0.27 & 0.52 & -0.20 & 0.65 \\
$I$ & -0.66 & 0.08 & -0.43 & 0.29 \\
$I_{\max }$ & -0.76 & 0.03 & -0.83 & 0.01 \\
$V$ & -0.57 & 0.15 & -0.69 & 0.06 \\
ADWP & 0.66 & 0.07 & 0.65 & 0.08 \\
\hline
\end{tabular}

There is no correlation between the $\mathrm{FF}_{30}$ and rainfallrunoff characteristics except event maximum rainfall intensity $\left(I_{\max }\right)$ according to the $p$-values. The $\mathrm{FF}_{30}$ of TSS is negatively and strongly correlated to the maximum rainfall intensity. The result was different from the previous study. Deletic (1998) and Taebi and Droste (2004) concluded that the magnitude of first flush is positively and strongly correlated to the maximum rainfall intensity. The results in this study show that the rain events with high maximum intensity do not always cause a more distinctive first flush. If the rainfall intensity maximum appears earlier, it would cause a more distinctive first flush. On the contrary, if the time of the rainfall intensity maximum appearance from the start of the event is later, it would cause a relatively weak first flush when there are enough pollutants available for wash-off to continue, e.g., for the event of June 26, 2005. Consequently, the rainfall pattern is a major factor that influences the washoff process.

The magnitude of first flush of TSS was correlated to the antecedent dry weather period. The rain events with longer antecedent dry weather condition were more likely to result in the higher first flush.

Previous studies concluded that the first flush is complex and site specific (Bertrand-Krajewski et al., 1998; Taebi and Droste, 2004; Kim et al., 2005). In comparison with other urban catchments reported by the above studies, the magnitude of the first flush is stronger in Shilipu catchment. Further, the $\mathrm{FF}_{30}$ in this study does not spread over a wide range around the mean values, as standard deviation coefficients and variation coefficients indicate. These results can be explained by the fact that Shilipu catchment is located in the wet region characterized by high intensity rain events. The wash-off capacities of these rain events could be sufficient to flush out the catchment surface and sewer system. Lee and Bang (2000) concluded that first flush occurs strongly as the proportion of impervious area higher. So the high proportion of impervious area $(85 \%)$ in this catchment is another reason for the significant first flush.

Shilipu catchment has a combined sewer system. Wastewater treatment plant is being constructed to intercept wastewater for treatment. But the wastewater from this catchment is not intercepted and directly discharged into the nearest Moshuihu Lake during the period of experiments. As a result, the storm runoff pollution loads measured at the catchment outlet partly originated from urban wastewater. However, the contribution of urban wastewater to the total pollution load was limited because urban wastewater flow was far less than storm runoff flow in times of storm (Figs.1 and 2). For example, urban wastewater contributed only for $4 \%$ of TSS, $9 \%$ of COD, $18 \%$ of TN and $14 \%$ of TP during the entire period of strom runoff on August 3, 2005. Therefore, most of total pollution loads measured at the catchment was primarily derived from the wash-off of catchment surface and the erosion of in-sewer sediments by storm runoff.

Additionally, if the wastewater treatment plant (WWTP) was established and urban wastewater was intercepted, a part of storm runoff will be sent to the WWTP for treatment during storms in future. When the flow threshold value to WWTP is selected equal to twice the average wastewater flow (that is the normal design threshold level used in China) in times of storms, a part of storm runoff pollution loads would be diverted to WWTP. For example, about $30 \%$ of the total pollution loads would be intercepted to WWTP during the entire period of strom runoff on August 3, 2005. The remaining about $70 \%$ of the total pollution loads would be discharged into Moshuihu Lake by overflow. 
Therefore, other measures are still needed to reduce the pollution loads from storm runoff. The first flush should be taken into account selecting management measures of storm runoff pollution for Shilipu catchment. Intercepting the early part of runoff volume (i.e., less than $30 \%$ ) is more effective and economical.

\section{Conclusions}

The pollutant concentration peaks preceded the flow peaks for all the storm events monitored, which means that the first flush occurred in the old urban area with a combined sewer system. The interval between the concentration peak and the flow peak was shorter for the events with higher rainfall intensity during the initial period of rainfall.

The means of $\mathrm{FF}_{30}$ values of TSS, COD, TN, and $\mathrm{TP}$ are $62.4 \%, 59.4 \%, 46.8 \%$, and $54.1 \%$, respectively. Intercepting the early part of runoff volume (i.e., less than $30 \%$ ) is more cost-effective for Shilipu catchment.

The events with longer antecedent dry weather condition were more likely to result in the higher pollution load.

\section{References}

APHA-AWWA-WPCF. 1998. Standard methods for the examination of water and wastewater [M]. 20th ed. Washington DC, USA.

Bertrand-Krajewski J L, Chebbo G, Saget A, 1998. Distribution of pollutant mass vs. volume in stormwater discharges and the first flush phenomenon[J]. Water Research, 32: 23412356.

Characklis, G W, Wiesner M R, 1997. Particles, metals, and water quality in runoff from large urban watershed[J]. Journal of Environmental Engineering, 123(8): 753-759.

Deletic A, 1998. The first flush load of urban surface runoff[J]. Water Research, 32: 2462-2470.

Ebina J, Tsutsui T, Shirai T, 1983. Simultaneous determination of total nitrogen and phosphorus in water using peroxodisulfate oxidation[J]. Water Research, 17: 1721-1726.

Gnecco I, Berretta C, LanZa L G et al., 2005. Storm water pollution in the urban environment of Genoa, Italy[J]. Atmospheric Research, 77: 60-73.

Kim L H, Kayhanian M, Zoh K D et al., 2005. Modeling of highway stormwater runoff[J]. Science of the Total Environment, 293: 163-175.

Lee J H, Bang K W, Ketchum L H et al., 2002. First flush analysis of urban storm runoff[J]. Science of the Total Environment, 293: 163-175.

Suarez J, Puertas J, 2005. Determination of COD, BOD, and suspended solids loads during combined sewer overflow (CSO) events in some combined catchments in Spain[J]. Ecological Engineering, 24: 201-219.

Taebi A, Droste R L, 2004. First flush pollution load of urban stormwater runoff[J]. Journal of Environmental Engineering, 3: 301-309.

US EPA. 1998. Water quality conditions in the United States: a profile from the 1996 National Water Quality Inventory Report to Congress[R]. Office of Water, Washington, DC. http://www.epa.gov/305b/96report/index.html. 